REVIEW ARTICLE

\title{
Adverse effects, pharmacological interactions, and cardiovascular drugs in COVID-19 treatment
}

\author{
Interacción farmacológica, efectos adversos y drogas cardiovasculares en el tratamiento \\ del COVID-19
}

\author{
Eduardo Chuquiure-Valenzuela ${ }^{1 *}$, Patricia Chuquiure-Valenzuela², María J. Chuquiure-Gil ${ }^{3}$, \\ María P. Bobadilla-Chuquiure ${ }^{4}$, Javier Chuquiure-Valenzuela ${ }^{5}$, and Eduardo Chuquiure-Lardizabal ${ }^{6}$
}

${ }^{1}$ Department of Clinical Cardiology, National Institute Cardiology Ignacio Chávez, Mexico City, Mexico; ${ }^{2}$ Cardiovascular Post-Surgical Unit, National Institute of Child Health, Lima, Peru; ${ }^{3}$ School of Medicine, Monterrey Institute of Technology and Higher Education. Monterrey, Mexico; ${ }^{4}$ School of Medicine, Cayetano Heredia University, Lima, Peru; ${ }^{5}$ nstitute of Cardiology and Cardiovascular Surgery, Juaneda Miramar Hospital, Palma de Mallorca, España; ${ }^{6}$ School of Medicine, Universidad Nacional Mayor de San Marcos, Lima, Peru

\begin{abstract}
In severe coronavirus disease (COVID)-19 patients, an extraordinary systemic inflammatory response is seen. It could impact in multiple organ disorders, specially a severe myocardial injury, an acute myocarditis results in focal or global myocardial inflammation and necrosis. Those events can be present in healthy subjects or cardiovascular (CV) patients. It is clinically associated with ventricular dysfunction exacerbation or worsening and tachyarrhythmias. It is also related to a poor outcome for CV patients with ischemic heart disease, hypertensión, and heart failure. COVID-19 patients require multiple and complex treatment that alleviates symptoms, the vast variety of agents interacts with diseases and $\mathrm{CV}$ drugs. Our purpose is to correlate in guidance synopsis: Adverse effects, pharmacological interactions, and CV drugs in COVID-19 treatment
\end{abstract}

Key words: Cardiovascular drugs. Pharmacology interactions. Adverse effects. COVID-19.

\section{Resumen}

En pacientes con COVID-19 grave se ha observado una extraordinaria respuesta inflamatoria sistémica. Este impacto se traduce en múltiples trastornos de órganos, especialmente cardíacos, por lesión miocárdica grave, miocarditis aguda que resulta en inflamación focal o miocárdica global, necrosis cardiaca. Estos tremendos eventos son observados en sujetos sanos como pacientes cardiovasculares. Clínicamente asociados con nueva presentación o empeoramiento de la disfunción ventricular y taquiarritmias. Relacionado a un predictor principal de malos resultado en pacientes cardiovasculares (CV), especialmente en aquellos con cardiopatía isquémica, hipertensión e insuficiencia cardíaca. Los enfermos con COVID-19 requieren múltiples y complejos tratamientos que alivien los síntomas, esta gran variedad de agentes interactúa con enfermedades y medicamentos CV. Nuestro propósito es correlacionar, en una guía sinóptica: efectos adversos, interacciones farmacológicas y fármacos cardiovasculares en el tratamiento del COVID-19.

Palabras clave: Drogas cardiovasculares. Interacciones farmacológicas. Efectos adversos. COVID-19.

Correspondence:

*Eduardo Chuquiure-Valenzuela

E-mail: echuquiurev@yahoo.com license (http://creativecommons.org/licenses/by-nc-nd/4.0/).

Date of reception: 21-05-2020

Date of acceptance: 22-07-2020

DOI: 10.24875/ACM.20000234
Available online: $10-09-2020$ Arch Cardiol Mex. 2021;91(Supl):79-85 www.archivoscardiologia.com 
The new coronavirus disease (COVID-19) caused by the severe acute respiratory syndrome coronavirus-2 virus, has become a pandemic since its outbreak in December 2019 in Wuhan, China'. The transmission of COVID-19 has had severe temporal and regional impacts, expanded throughout Asia at the end of 2019; in February 2020, there were marked increases in patients in Europe, invariably, in the Americas, acceleration of incidence was observed from March 2020.

COVID-19 infection is a serious public health problem that has forced health workers and authorities to take priority health measures, in disease pathophysiology knowledge, effective treatment research, and prevention measures ${ }^{2}$.

The enter pathway of viral particles is mainly through the respiratory system ${ }^{3}$, generating a local symptom, flu-like, fever, or cough ${ }^{4-6}$. In the next few hours, a severe compromise due to an exaggerated immune response is observed causing significant systemic deterioration, particularly respiratory and hemodynamic ${ }^{4-9}$. Tavazzi et al. reported myocardium viral invasion ${ }^{10}$ that describes the deleterious mechanisms of myocardial and hemodynamic malfunction ${ }^{7-9}$. These alterations are associated with highly intensive care hospitalization rates adding poor prognosis and high mortality. Cardiac damage could involve both previously disease-free and cardiovascular (CV) patients, with poor prognosis associated to increased mortality.

Adverse CV conditions have been hypothesized, such as an acute myocardial dysfunction induced or added to a severe inflammatory or toxic sepsis ${ }^{11}$ in COVID-19 patients. Associated to a main predictor of poor outcome, history of CV comorbidities (e.g., ischemic heart disease, hypertension, etc.) is an important risk factor for worsening prognosis ${ }^{11,12}$. An extraordinary systemic inflammatory response could mediate severe myocardial injury $y^{9,10,12}$. In several cases, acute myocarditis results in focal or global myocardial inflammation and necrosis ${ }^{9,11}$. It is also related to worsening ventricular dysfunction and tachyarrhythmias ${ }^{11-13}$.

Our purpose is to correlate, in guidance synopsis: a general adverse effects (AEs), pharmacological interactions, CV side effects, as well as interaction with CV drugs, principally in relation with concomitant use of treatment for COVID-19

With the current COVID-19 pandemic, CV patients could have five probable therapeutic scenarios ${ }^{11-13}$ : (1) routine CV treatment, (2) agents to relieve mild to moderate COVID-19 symptoms, (3) viral load reducing drugs, (4) anti-inflammatory agents, and (5) advanced support of Intensive care units.
In the current treatment, many CV patients have been related to multiple concomitant comorbidities, chronically controlled with multiple agents (antihypertensive, anticoagulants, antiarrhythmics, statins, and among others). Many cardiological societies and government agencies recommend continuing treatment at optimal doses for proper comorbidities control. There are few clinical evidences of $A E$ with angiotensin-converting enzyme inhibitors and angiotensin receptor blockers ${ }^{11,13}$ and symptomatic treatment relief concomitant symptoms (fever, myalgia, odynophagia, and headache)

In specific COVID-19 treatment, multiple drug treatments ${ }^{11-14}$ have been tested: antimalarials (hydroxychloroquine/chloroquine); antivirals: protease inhibitors (lopinavir/ ritonavir and darunavir/ritonavir) and nucleotide analogs (remdesivir); anthelmintics (ivermectin); and immunotherapy (immunoglobulin), antibiotics (azithromycin) and monoclonal antibodies (tocilizumab), and corticosteroid.

\section{Antimalarials}

Since the onset of COVID-19 pandemic, antimalarials (hydroxychloroquine and chloroquine) potential beneficial use was hypothesized, Food and Drug Administration (FDA) authorized its emergency use promptly ${ }^{15}$. Later, new clinical information studies ${ }^{16,17}$ have found that hydroxychloroquine did not show benefits for patients with COVID-19 and did not prevent viral exposed, so the use was discontinued.

\section{Currently, these drugs are not recommended for this indication}

Hydroxychloroquine and chloroquine have immunomodulatory properties, inhibit viral entry, by increase endosomal and lysosomal $\mathrm{pH}$ and attenuating virus ability to release its genetic material into the cell ${ }^{15}$. Its use can result in retinopathy and ototoxicity ${ }^{14}$. Hypoglycemia, neurological alterations, and hepatotoxicity were reported. Patients with renal failure require correction dose ${ }^{14}$.

Antimalarials produce CV alterations, it modulates coronary arterial vasodilation by nitric oxide production reductions in coronary artery endothelial cells. On the other hand, antimalarials alter diastolic performance, and produces myocardial fibrosis and arrhythmias ${ }^{15}$. Cardiotoxicity and cardiac AE were associated to longterm used and dose dependent ${ }^{12}$. Ventricular arrhythmias and torsade de pointes were reported ${ }^{13,14}$. Bundle branch block, atrioventricular block, and prolonged QT were associated $(<10 \%)^{14}$. Baseline and follow-up 
electrocardiography were recommended ${ }^{12,14}$. Antimalarials increase levels of mammalian target of rapamycin inhibitors, calcineurin inhibitors, and beta-blockers. Aspirin decreases antimalarial levels. Antimalarials with antiarrhythmics are contraindicated for prolongation of the QT interval ${ }^{14}$ (Table 1).

\section{Antivirals}

Protease inhibitors such as lopinavir/ritonavir and darunavir/ritonavir are antiviral combinations, who demonstrated inhibition activity against coronavirus$\mathrm{es}^{11-14}$. Some AE are gastrointestinal such as nausea and diarrhea, and hepatotoxicity, increased alanine aminotransferase (ALT) serum levels and pancreatitis. Hematological: hemolytic anemia, neutropenia, and increase bleeding were reported. Hyperglycemia and skin reactions were seen.

Lopinavir/ritonavir regulates of fatty acid oxidation and cholesterol synthesis, increasing serum levels, and elevates myocardial oxidative stress and concomitantly inhibits the ubiquitin proteasome system, associated with depressed contractility and cardiac hypertrophy. An altered connexin 43 expression may be linked to perturbed gap junction assembly and arrhythmogenesis, it can precede ventricular fibrillation in rat models ${ }^{18}$.

CV AE was prolonged QT and PR intervals and $2^{\text {nd }}$ and $3^{\text {rd }}$ degree heart block ${ }^{11-14}$. Hyperlipidemia was also associated. CV drugs such as antiarrhythmics amiodarone, flecainide, ivabradine, ranolazine, lovastatin, pitavastatin, and simvastatin are contraindicated ${ }^{14}$. Antivirals increase level of antiplatelets, beta-blockers, calcium channel blockers, digoxin, mineralocorticoids receptor agents, and direct oral anticoagulant. The use of antivirals with warfarin presented variable effects on the international normalized ratio (INR) $)^{14}$. Serious effects report and use alternative recommended with bosentan, propafenone, rivaroxaban, edoxaban, and sildenafil (Table 1).

Remdesivir is a nucleotide analog who inhibits viral RNA polymerases, FDA approved a compassionate use $^{19}$. Remdesivir is a substrate of several cytochrome P450 enzymes in vitro, however, clinical implications are unclear since the pro-drug is rapidly metabolized by plasma hydrolases ${ }^{20}$. Any CV action is ignored. General AE is increased hepatic enzymes, diarrhea, hypernatremia, and renal impairment. CV AE was seen in a compassionate study, deep vein thrombosis atrial fibrillation hypotension ${ }^{5}$ (Table 1). Wang et al. ${ }^{21}$ reported no serious CV AE (tachycardia and acute coronary syndrome).

\section{Adjunctive therapies}

\section{Monoclonal antibody}

Tocilizumab is a monoclonal antibody who binds to interleukin (IL)-6 receptor to prevent activation and signaling ${ }^{11,13}$. Tocilizumab decreases lipoprotein-A levels and could be responsible for high-density lipoprotein cholesterol loss of antiatherogenic function ${ }^{22}$. An observational study associates tocilizumab to an increased left ventricular (LV) ejection fraction and decreased LV mass index ${ }^{23}$. General side effects include rise in serum ALT, pancreatitis, gastritis, and neutopenia ${ }^{14}$. Hypertension and dyspnea should be monitored closely ${ }^{14}$. No interactions with CV drugs were reported.

\section{Anthelmintics}

Ivermectin is an FDA-approved anti-parasitic agent which was also proven to exert antiviral activities ${ }^{24}$. $\mathrm{AE}$ was hepatic, neurological, skin reactions, and interference with Vitamin $\mathrm{K}$ metabolism ${ }^{25}$ - CV interactions are not described. Hypotension and nonspecific electrocardiogram (EKG) changes were close monitoring. Interactions reported with antiarrhythmics, calcium channel blockers, statin, and warfarin ${ }^{25}$ (Table 1).

\section{Antibiotics}

Azithromycin is a macrolide who prevents bacterial superinfection and may have immunomodulatory properties $^{11}$. It inhibits protein synthesis, decreases inflammation and viral replication ${ }^{26}$. Also, reduces cyotkine reproduction ${ }^{1}$, neutrophil chemotaxis and improves apoptosis ${ }^{11,13,14}$. General AE reported was diarrhea associated to clostridium difficile, abnormal liver function, cholestatic jaundice, and myasthenia gravis symptoms ${ }^{14}$. Serious CV side effects are uncommon ${ }^{27}$, however, they may include prolonged QT interval, risk of developing ventricular tachycardia, and torsades de pointes, especially in the elderly, in uncorrected hypokalemia or hypomagnesemia, in pre-existing QT interval prolongation or those taking anti-arrhythmic drugs ${ }^{26,27}$ (Table 1). The mechanism of induced QT prolongation is the inhibition of repolarization of cardiac cells through potassium channels ${ }^{28}$. 


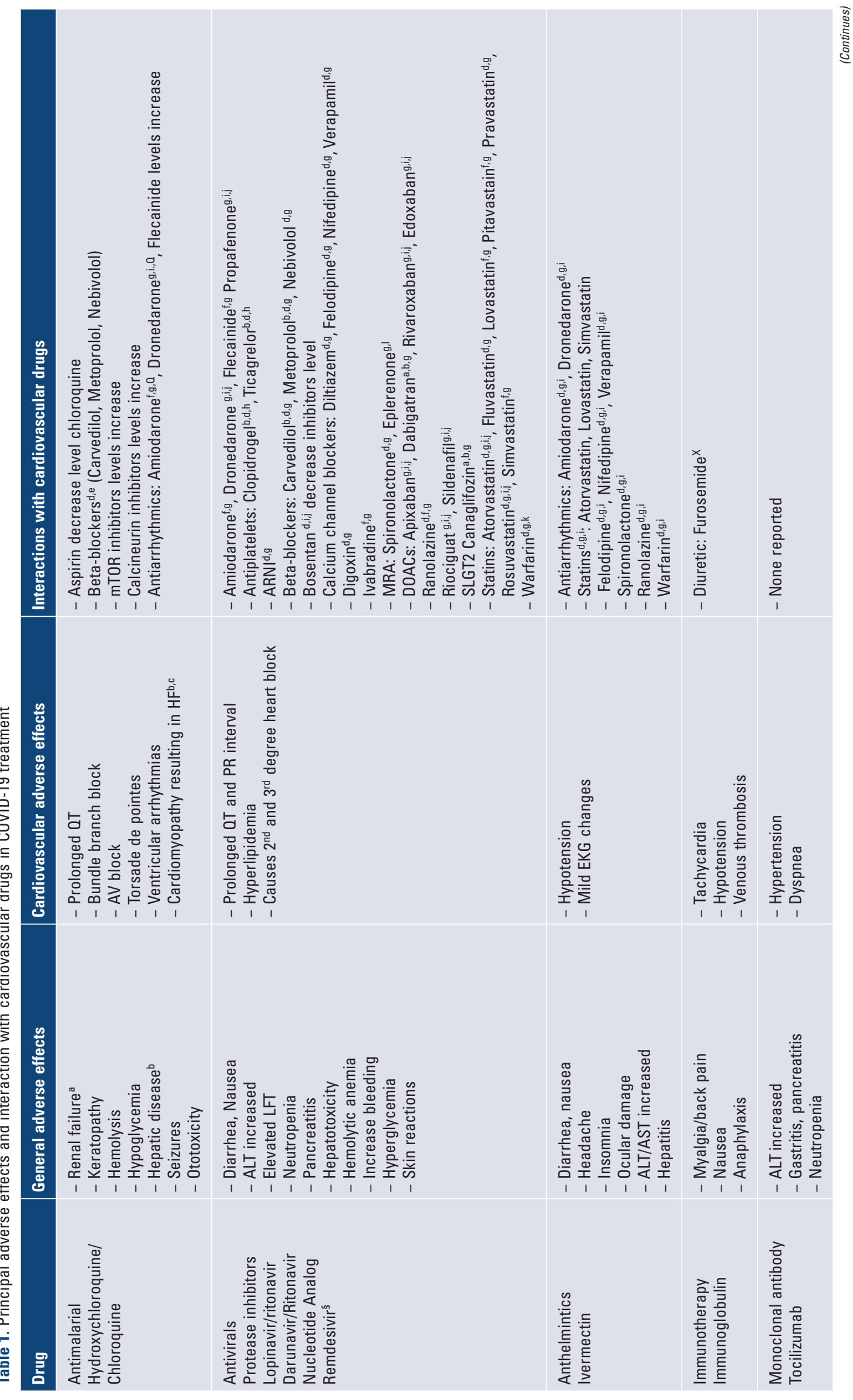




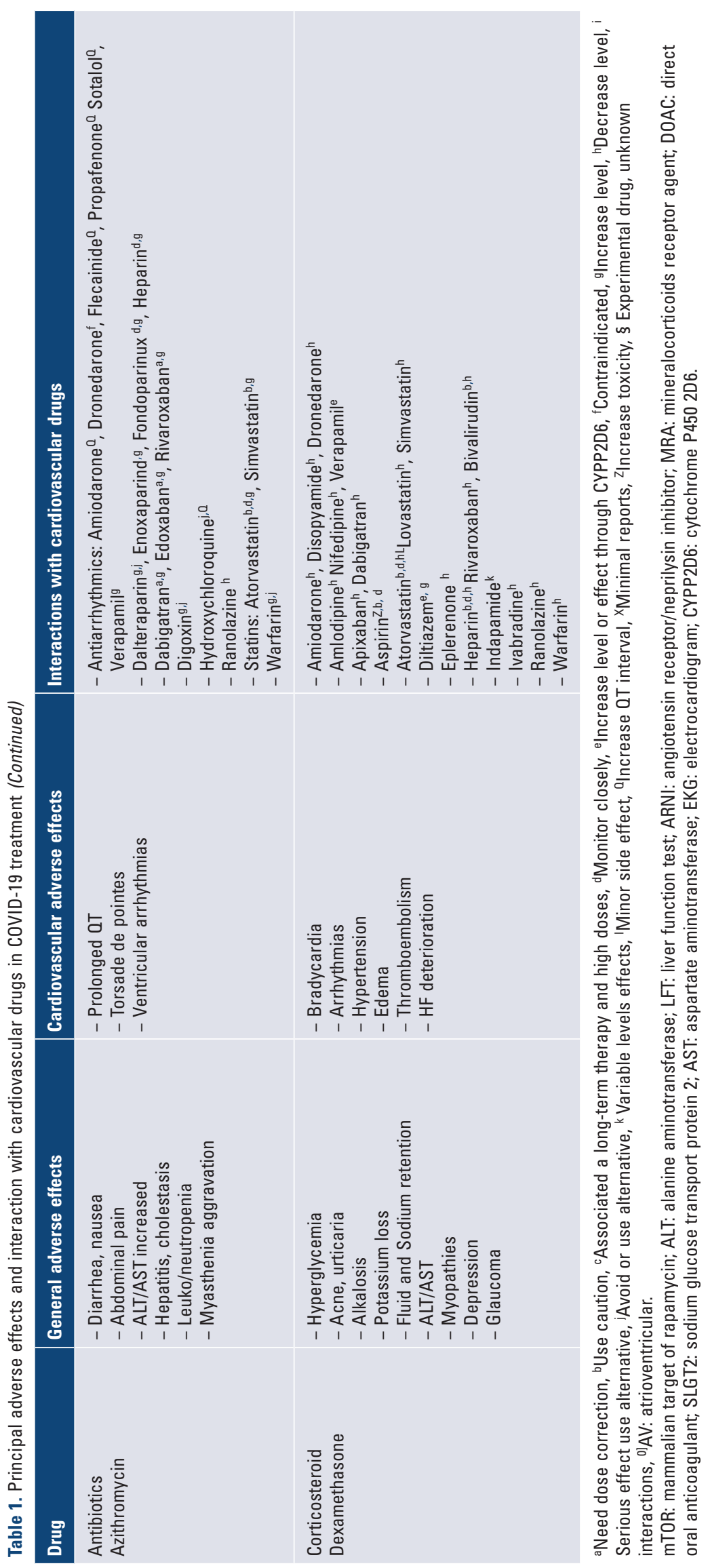




\section{Immunotherapy (immunoglobulin)}

It is hypothesized that antibodies from recovered patients may help with both free virus and infected cell immune clearance ${ }^{11}$. Anaphylaxis, myalgia, back pain, and nausea were the principal $\mathrm{AE}^{14}$. Supraventricular tachycardia and bradycardia were reported in patients who had history of heart disease ${ }^{29}$, its mechanism is uncertain. Hypotension is a rare symptom related to immunoglobulin. Arterial or venous thrombosis was reported as serious $A E^{29}$. Related acute lung injury was associated, uses with caution.

\section{Dexamethasone}

Severe COVID-19 patients may present cytokine storm that is associated to lung involvement of acute respiratory distress syndrome (ARDS) and multiorgan failure ${ }^{8,9}$. $A$ therapeutic that may modulate and antagonize viral mediated hyperinflammation is dexamethasone, a corticosteroid, that can inhibit pro-inflammatory mediators ${ }^{30}$ such as $\mathrm{C}$-reactive protein, tumor necrosis factor, IL, and also reduce the production of inflammatory autacoids ${ }^{30}$ (prostaglandins, prostacyclin, leukotrienes, and thromboxane ${ }^{26}$ ), observed in severe ARDS patients. Recent preliminary evidence suggests that dexamethasone reduced mortality in invasive mechanical ventilation in COVID-19 patients ${ }^{31}$. Dexamethasone had actions in several organs and systems (endocrine, metabolic, etc.). General AE includes hyperglycemia, alkalosis, potassium loss, sodium retention, increase of ALT/AST serum levels, acne, and urticaria. Myopathies, glaucoma, and depression were related. CV AE such as hypertension, edema, and heart failure deterioration was associated to secondary sodium retention. It increases the risk of developing venous thromboembolism. Bradycardia and arrhythmias were also associated.

\section{Conclusions}

The source of our references is based on recent publications as well as online technology applications with pharmacopoeia information.

We believe this article, describes an important clinical perspective that could improve hospital therapeutic considerations, personalized pharmacovigilance, contribute, and help in daily clinical practice, which we add just in one table.

In general, these studies are limited because most of the recent COVID-19 reviews are case reports, with small retrospective or non-randomized studies and regional bias. It is important to emphasize the CV-AE resulting from the interaction of both CV and COVID-19 medications.

Physiopathological, clinical, therapeutic, and pronostic interactions in a new disease are dynamically changing according to advances in scientific research.

\section{Funding}

This research has not received any specific grants from agencies in the public, commercial, or non-profit sectors.

\section{Conflicts of interest}

PCHV, MCHG, MBCH, JCHV, and ECHL declare no conflicts of interest. ECHV declares personal fees as: speaker: Bayer de México, Servier México, Sanofi, México Stendhal. Consulting: Aliados estratégicos en salud y nutrición S.C. and Servier México. Honoraria for participation in clinical trial: Boehringer Ingelheim. All authors comply with the authorship criteria of the International Committee of Medical Journal Editors (ICJME), and all have approved the final manuscript and agree to this submission.

\section{Ethical disclosures}

Protection of human and animal subjects. The authors declare that no experiments were performed on humans or animals for this study.

Confidentiality of data. The authors declare that no patient data appear in this article.

Right to privacy and informed consent. The authors declare that no patient data appear in this article.

\section{References}

1. Caraballo C, McCullough M, Fuery M, Chouairi F, Keating C, Ravindra N, et al. COVID-19 infections and outcomes in a live registry of heart failure patients across an integrated health care system. medRxiv. 2020. [Epub ahead of print].

2. European Society of Cardiology ESC Guidance for the Diagnosis and Management of CV Disease during the COVID-19 Pandemic. Available from: https://www.escardio.org/Education/COVID-19-and-Cardiology/ ESC-COVID-19-Guidance. [Last accessed on 2020 Jul 05].

3. Tay M, Poh C, Rénia L, MacAry PA, Ng LF. The trinity of COVID-19: immunity, inflammation and intervention. Nat Rev Immunol. 2020;20:363-74.

4. Clerkin K, Fried J, Raikhelkar J, Sayer G, Griffin JM, Masoumi A, et al. Coronavirus disease 2019 (COVID-19) and cardiovascular disease. Circulation. 2020;141:1648-55.

5. Tang C, Zhang K, Wang W, Pei Z, Liu Z, Yuan P, et al. Clinical characteristics of 20,662 patients with COVID-19 in mainland China: a systemic review and meta-analysis. medRxiv. 2020. [Epub ahead of print].

6. Madjid M, Safavi-Naeini P, Solomon S, Vardeny O. Potential effects of coronaviruses on the cardiovascular system: A review. JAMA Cardiol. 2020;5(7):831-40 


\section{E. Chuquiure-Valenzuela, et al.: COVID-19 and cardiovascular side effects}

7. Tersalvi G, Vicenzi M, Calabretta D, Biasco L, Pedrazzini G, Winterton D. Elevated troponin in patients with coronavirus disease 2019: possible mechanisms. J Card Fail. 2020;26:470-5.

8. Tomasoni D, Italia L, Adamo M, Inciardi RM, Lombardi CM, Solomon SD, et al. COVID-19 and heart failure: from infection to inflammation and angiotensin II stimulation. Searching for evidence from a new disease. Eur J Heart Fail. 2020;2020:1871.

9. Richardson S, Hirsch JS, Narasimhan M, Crawford JM, McGinn T, Davidson $\mathrm{KW}$, et al. Presenting characteristics, comorbidities, and outcomes among 5700 patients hospitalized with COVID-19 in the New York city area. JAMA. 2020;323:2052-9.

10. Tavazzi G, Pellegrini C, Maurelli M, Belliato M, Sciutti F, Bottazzi A, et al Myocardial localization of coronavirus in COVID-19 cardiogenic shock. Eur J Heart Fail. 2020;22:911-5.

11. Tu $Y$, Chien $C$, Yarmishyn A, Lin $Y Y$, Luo $Y H$, Lin $Y T$, et al. A review of SARS-CoV-2 and the ongoing clinical trials. Int J Mol Sci. 2020;21:2657.

12. Sander J, Monogue M, Jodlowski T, Cutrell J. Pharmacologic treatments for coronavirus disease 2019 (COVID-19) A Review. JAMA 2020;323(18):1824-36

13. Smith T, Bushek J, LeClaire A, Prosser T. COVID-19 Drug Therapy Clinical Drug Information. Clinical Solutions. Available from: https://www. elsevier.com/_data/assets/pdf_file/0016/1004173/COVID-19-Drug-Therapy_4.30.2020.pdf. [Last accessed on 2020 Jul 04].

14. Medscape Drug. Available from: https://www.reference.medscape.com.

15. Becker R Covid-19 treatment update: follow the scientific evidence. J Thromb Thromb. 2020;50:43-53.

16. Recovery Trial. Available from: https://www.recoverytrial.net. [Last accessed on $2020 \mathrm{Jul}$ 03].

17. Boulware D, Pullen M, Bangdiwala A, Pastick KA, Lofgren SM, Okafor $\mathrm{EC}$, et al. A randomized trial of hydroxychloroquine as postexposure prophylaxis for covid-19. N Engl J Med 2020. [Epub ahead of print]

18. Reyskens K, Fisher T, Schisler J, O'Connor WG, Rogers AB, Willis MS et al. Cardio-metabolic effects of HIV protease inhibitors (lopinavir/ritonavir). PLoS One. 2013;8:e73347.

19. Grein J, Ohmagari N, Shin D, Diaz G, Asperges E, Castagna A, et al. Compassionate use of remdesivir for patients with severe covid-19. N Engl J Med. 2020;382:2327-36.
20. Jorgensen S, Kebriaei R, Dresser L. Remdesivir: review of pharmacology, pre-clinical data and emerging clinical experience for COVID-19. Pharmacotherapy. 2020;40:659-71.

21. Wang Y, Zhang D, Du G, Du R, Zhao J, Jin Y, et al. Remdesivir in adults with severe COVID-19: a randomized, double-blind, placebo-controlled, multicentre trial. Lancet. 2020;395:1569-78.

22. Castagné B, Viprey M, Martin J. Cardiovascular safety of tocilizumab: a systematic review and network meta-analysis PLoS One. 2019; 14:e0220178.

23. Kobayashi H, Kobayashi Y, Giles JT, Yoneyama K, Nakajima Y, Takei M. Tocilizumab treatment increases left ventricular ejection fraction and decreases left ventricular mass index in patients with rheumatoid arthritis without cardiac symptoms: assessed using 3.0 tesla cardiac magnetic resonance imaging. $J$ Rheumatol. 2014;41:1916-21.

24. Calya L, Drucea J, Cattona M. The FDA-approved drug ivermectin inhibits the replication of SARS-CoV-2 in vitro. Anti Res. 2020;178:104787.

25. González A, Sahagun A, Diez J, Martínez NF, Vega MS, Vieitez JJ. The pharmacokinetics and interactions of ivermectin in humans-a mini-review. AAPS J 2008;10:42-6.

26. Schwartz R. Suskind azithromycin and COVID-19 prompt early use at first signs of this infection in adults and children an approach worthy of consideration. Dermatol Ther. 2020;2020:e13785.

27. Ray W, Murray K, Hall K, Arbogast PG, Stein CM. Azithromycin and the risk of cardiovascular death. N Engl J Med. 2012;366:1881-90.

28. Kumaresan R, Palaian S, Thapa S, Shankar PR. Risk of cardiovascular effects with azithromycin. J Clin Diagn Res. 2015;9:FL01

29. Guo $Y$, Tian $X$ Wang $X$. Adverse effects of immunoglobulin therapy. Front Immunol. 2018. [Epub ahead of print].

30. Veronese N, Demurtas J, Yang L, Tonelli R, Barbagallo M, Lopalco P, et al. Use of corticosteroids in coronavirus disease 2019 pneumonia: a systematic review of the literature. Front Med. 2020;7:170.

31. Horby P, Shen W, Emberson J, Mafham M, Bell J, Linsell L, et al. Effect of dexamethasone in hospitalized patients with COVID-19. Preliminary report. medRxiv 2020. [Epub ahead of print]. 